\title{
PENGARUH EM, SIZE, ROE DAN LEV TERHADAP DPR PADA PERUSAHAAN MANUFAKTUR YANG TERDAFTAR DI BEI TAHUN 2014-2016
}

\author{
Rini Tri Hastuti \\ Fakultas Ekonomi Universitas Tarumanagara Jakarta \\ Email: rinih@fe.untar.ac.id
}

\begin{abstract}
The purpose of this research is to examine the effect ofearnings management, firm size, return on equity and dividend payoutratio on manufacturing companies listed in the Indonesian Stock Exchange in 2014-2016.The sample was determined by purposive sampling method. The research conducted by taking 117 manufacturing companies. The result of this research showed that earnings management and firm size have no significant effect on dividend payoutratio, while return on equity and leverage have significant effect on dividend payoutratio.
\end{abstract}

Keywords: Dividend PayoutRatio(DPR), Earnings Management (EM), Firm Size (SIZE), Return on Equity (ROE), Leverage (LEV).

\begin{abstract}
Abstrak: Tujuan penelitian ini adalah untuk menguji pengaruh manajemen pembelajaran, ukuran perusahaan, return on equity dan dividend payoutratio pada perusahaan manufaktur yang terdaftar di Bursa Efek Indonesia tahun 2014-2016. Sampel ditentukan dengan metode purposive sampling. Penelitian dilakukan dengan mengambil 117 perusahaan manufaktur. Hasil penelitian menunjukkan bahwa manajemen laba dan ukuran perusahaan tidak berpengaruh signifikan terhadap dividend payoutratio, sedangkan return on equity dan leverage berpengaruh signifikan terhadap dividend payoutratio.
\end{abstract}

Kata Kunci: Dividend PayoutRatio (DPR), Manajemen Laba (EM), Ukuran Perusahaan (SIZE), Return on Equity (ROE), Leverage (LEV).

\section{PENDAHULUAN}

Saat ini di Indonesia, persaingan dalam usaha sudah sangat kompetitif,sehingga perusahaan harus melakukan apapun agar perusahaan dapat mempertahankan kelangsungan hidupnya. Disamping dalam hal menghasilkan produk yang tentunya produk tersebut dapat memuaskan konsumen, perusahaan juga harus mampu mengelola keuangan dengan baik. Salah satu faktor yang mempengaruhi perusahaan dalam membangun citra perusahaan agar baik bagi pemangku kepentingan dan bagi para pemegang saham adalah kebijakan dividen. Hal ini dapat dilihat dari jumlah perusahaan yang melakukan pembagian dividen.

Berikut merupakan fakta perusahaan manufaktur yang terdaftar di Bursa Efek Indonesia pada tahun 2012-2014 yang melakukan kegiatan pembagian dividen. Padatahun 2012, terdapat 90 perusahaan yang tidak membagikan dividen, dan 62 perusahaan yang membagikan dividen $(41 \%)$, padatahun 2013, terdapat95perusahaan yang tidak membagikan dividen dan 57perusahaan yang membagikan dividen (38\%), dan pada tahun 2014, terdapat 86 perusahaan yang tidak membagikan dividen dan 66 perusahaan yang membagikan 
dividen $(43 \%)$. Berdasarkan data mengenai pembagian dividen oleh perusahaan manufaktur yang terdaftar di Bursa Efek Indonesia pada tahun 2012-2014 dapat ditarik kesimpulan bahwa terdapat persentase perusahaan yang tidak bagi dividen

Dari data di atas maka peneliti akan menganalisis beberapa faktor-faktor yang mempengaruhi Dividend Payout Ratio (DPR) pada perusahaan manufaktur yang terdaftar di BEI periode 2014-2016 yaitu Earnings Management, Firm Size, Return on Equity dan Leverage.

\section{KAJIAN TEORI}

Bird in the hand theory, Myron Gordong dan John Lintner mengatakan bahwainvestor lebih memilih untuk menerima dividen tunai (bird in the hand) daripada janji atas perolehan capital gain di masa yang akan datang(two in the bush). Hal ini dikarenakan dividen memiliki tingkat kepastian yang lebih tinggi dibandingkan dengan capital gain beserta penerimaan dividen yang sudah pasti jumlah nominalnya dibandingkan dengan capital gain yang nilai nominalnya yang dapat berubah-ubah.

Life cycletheory, Fama dan French (2011) menjelaskan bahwabesar kecilnya arus kas bebas bergantung pada kebutuhan modal dalam membiayai pertumbuhan perusahaan. Pada umumnya, bagi perusahaan baru maupun bagi perusahaan yang masih dalam tahap pertumbuhan cenderung memiliki peluang investasi yang besar sehingga memiliki arus kas bebas yang rendah dan akan berefek pada kemampuan pembayaran dividen yang rendah. Namun, berbeda dengan perusahaan yang berada dalam tahap kedewasaan terhadap proyek yang menguntungkan. Dimana, perusahaan dalam tahap seperti ini cenderung memiliki dana yang murah sehingga pembayaran dividen yang diperoleh cenderung tinggi.

Dividend Payout Ratio.Irham Fahmi (2015), "suatu keadaan dimana perusahaan memilih untuk membagikan dividen atas laba maka hal ini akan mengurangi besar laba yang ditahan serta kemudian akan mengakibatkan total sumber dana baik yang berasal dari dana internal ataupun internal financing". Sedangkan menurut Halim (2009) Dividend Payout Ratiomerupakan porsi dividen yang dibagikan oleh perusahaan akan menggambarkan tingkat pertumbuhan laba perusahaan saat ini dan masa mendatang atas perusahaan tersebut sehingga bagi perusahaan yang membagikan dividen dalam jumlah yang besar akan memberikan asumsi bahwa perusahaan tersebut baik bagi perusahaan itu sendiri, namun begitu sebaliknya bagi perusahaan yang membagikan dividen dengan porsi yang kecil hal ini akan menjadikan informasi yang kurang baik bagi perusahaan tersebut.

Earnings Managament. Scoot (2009), "suatu tindakan yang dilakukan manajemen dalam proses menyusun laporan keuangan untuk menaikkan dan menurunkan laba perusahaan untuk tujuan tertentu yang berdasarkan atas suatu kepentingan perusahaan.Tindakan tersebut disamping akan memperoleh manfaat, tindakan tersebut akan mengakibatkan penurunan kualitas dan kredibilitas laporan keuangan perusahaan bagi masyarakat yang berperan sebagai pengguna laporan keuangan tersebut". Sedangkan menurut Kristiani, dkk (2014) earnings managament merupakan suatukondisi dimana manajemen melakukan intervensi dalam proses penyusunan laporan keuangan dengan mempengaruhi angka-angka akuntansi agar sesuai dengan apa yang menjadi tujuan yang telah disusun untuk kepentingan perusahaan.

Firm size.Brigham dan Houston (2010), "rata-rata total atas penjualan bersih pada tahun berjalan hingga beberapa tahun berikutnya". Sedangkan menurut Kurniasih dan Sari 
(2013) firm size adalah ukuran suatu perusahaan dapat ditunjukkan dari total aset, kapitalisasi pasar, total penjualan dan nilai pasar saham.

Return on Equity.Kasmir (2017) "rasio yang dapat digunakan untuk mengetahui efisiensi atas penggunaan modal sendiri. Rasio ini merupakan suatu alat ukur antara laba bersih setelah pajak terhadap modal sendiri. Sehingga, perusahaan dengan return on equity yang semakin tinggi artinya kondisi perusahaan semakin baik dan semakin kuat begitu pula sebaliknya". Sedangkan Harahap, Sofyan Syafri (2015) menyatakan bahwa return on equitymerupakan rasio yang menunjukkan persentase perolehan laba bersih yang diukur dari modal perusahaan.

Leverage. Kasmir (2017) "rasio yang dapat mengukur sejauh mana penggunaan hutang oleh perusahaan dalam membiayai kegiatan operasional perusahaan ketimbang dengan menggunakan modalnya sendiri dan dapat mengetahui keseimbangan nilai aset tetap beserta modalnya". Sedangkan menurut Harahap, Sofyan Syafri (2015) leverage merupakan rasio yang dapat memberi gambaran mengenai seberapa jauh perusahaan tersebut dibiayai oleh hutang terhadap modal dan aset.

Kerangka pemikiran dalam penelitian ini seperti digambarkan dibawah ini

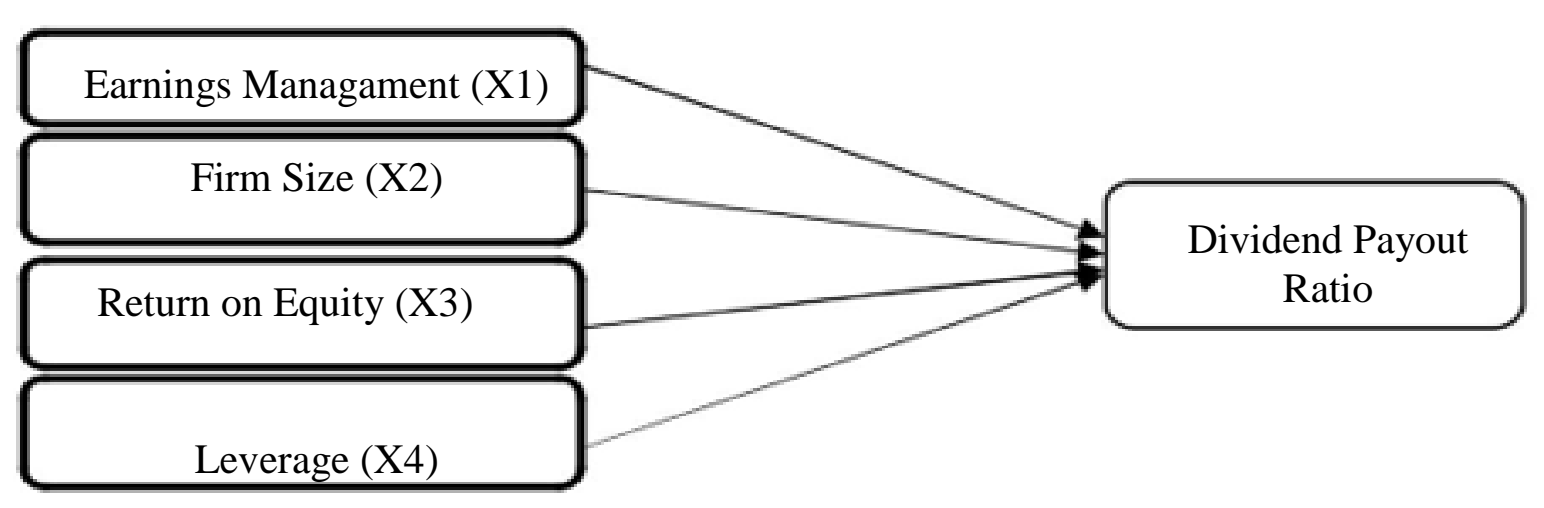

Gambar 1. Kerangka Pemikiran

Hipotesis dari model yang dibangun di atas adalah sebagai berikut :

$\mathrm{H}_{1}$ : Earnings Management berpengaruh secara negatif signifikan terhadap dividend payout ratio

$\mathrm{H}_{2}$ : Firm Size berpengaruh secara positif signifikan terhadap dividend navout ratio

$\mathrm{H}_{3}$ : Return on Equity berpengaruh positif signifikan terhadan dividend payout ratio

$\mathrm{H}_{4}$ : Leverage berpengaruh negatif signifikan terhadap dividend payout ratio

\section{METODE}

Objek Penelitian. Penelitian ini difokuskan pada seluruh perusahaan manufaktur yang terdaftar di Bursa Efek Indonesia Periode 2014-2016 yang laporan keuangannya didapat dari www.idx.ac.id. Pemilihan sampel dilakukan secara purposive sampling method dengan kriteria-kriteria yang ditentukan dalam pengambilan sampel penelitian ini yaitu: (a) Perusahaan manufaktur yang sudah go public dan terdaftar di BEI periode 2014-2016, (b) Perusahaan yang laporan keuangannya tidak menggunakan mata uang rupiah (asing), (c) 
Perusahaan yang tidak membayar dividen selama periode 2014-2016. ${ }^{3)}$ Jumlah data yang memenuhi syarat 39 perusahaan.

Variabel operasional dalam penelitian ini terdiri dari earnings management, firm size, return on equity dan leverage yang merupakan variabel independent dan dividend payout ratio sebagai variabel dependent. Dividend Payout Ratio. Dalam penelitian ini dividend payout ratio yang membandingkan dividend paid dengan net income dengan formula:

$$
\text { Dividend Payout Ratio }=\frac{\text { Dividend Paid }}{\text { Net Income }}
$$

Sedangkan firm size. Dalam penelitian ini firm size diwakili oleh Log Natural dari total aset.

$$
\text { Firm Size } \quad=\log (\text { Total Asset })
$$

Return on Equity. Dalam penelitian ini Return on Equity diwakili dengan membandingkan laba bersih sesudah pajak dengan dari total ekuitas.

$$
\text { Return on Equity } \quad=\frac{\text { Laba Bersih sesudah pajak }}{\text { Total Ekuitas }} \times 100 \%
$$

Sedangkan leverage. Dalam penelitian ini leverage diwakili oleh debt to equity ratio dengan membandingkan total kewajiban dengan total ekuitas.

$$
\text { DER } \quad=\frac{\text { Total Kewajiban }}{\text { Total Ekwitas }} \times 100 \%
$$

Dalam penelitian ini menggunakan Uji Statistik Deskriptif untuk menguji data sampel, kemudian menguji menggunakan model Pendekatan Kuadrat Terkecil (Common Effect Model),model Pendekatan Efek Tetap (Fixed Effect Model), model Pendekatan Efek Acak (Random Effect Model), model estimasi dalam data panel yaitu Pooled Least Square (PLS) dengan Fixed Effect Model (FEM) atau Fixed Effect Model (FEM) dengan Random Effect Model (REM).

Hasil Uji Statistik. Uji statistik deskriptif yang menggambarkan tentang ringkasan data penelitian seperti mean, standar deviasi, minimum, dan maksimum. Hasil statistik deskriptif untuk periode 2014 - 2016 menunjukkan bahwa dividend payout ratio (DPR) memiliki nilai minimum sebesar -2.010000 , nilai maksimum sebesar 1.540000 , nilai mean sebesar 0.403675 , dan standar deviasi sebesar 0.413642. Hasil statistik deskriptif untuk periode 2014 - 2016 menunjukkan bahwa firm size (SIZE) memiliki nilai minimum sebesar 25.62000, nilai maksimum sebesar 33.20000, nilai mean sebesar 28.95803, dan standar deviasi sebesar 1.752947. Hasil statistik deskriptif untuk periode 2014 - 2016 menunjukkan bahwa return on equity (ROE) memiliki nilai minimum sebesar -0.030000 , nilai maksimum sebesar 1.570000, nilai mean sebesar 0.243248, dan standar deviasi sebesar 0.297808. Hasil statistik deskriptif untuk periode 2014 - 2016 menunjukkan bahwa leverage (LEV) memiliki nilai minimum sebesar 0.080000 , nilai maksimum sebesar 5.150000, nilai mean sebesar 0.832479 , dan standar deviasi sebesar 1.104885 .

Hasil statistik deskriptif untuk periode 2014 - 2016 menunjukkan bahwa earnings management (EM) memiliki nilai minimum sebesar -0.183000 , nilai maksimum sebesar 0.535210 , nilai mean sebesar 0.000000171, dan standar deviasi sebesar 0.100036.

Tahap pertama adalah dengan membandingkan model mana yang akan dipilih antara Common Effect dan Fixed Effect.pengujian model Common Effect diperoleh hasil R-squared sebesar 0.198586 atau $19.85 \%$. Hal ini menunjukkan besarnya kontribusi variabel 
independen yang mampu menjelaskan variabel dependen dalam model common effect adalah sebesar $19.85 \%$. Pada model Common Effect terdapat dua dari empat variabel yang memiliki pengaruh signifikan terhadap variabel dependen. Dua variabel tersebut adalah Return on Equity dan Leverage. Setelah didapatkan hasil pengujian dari model Common Effect, proses selanjutnya adalah membandingkan model Common Effect dengan model Fixed Effect untuk dilihat model manakah yang lebih sesuai untuk digunakan dalam penelitian ini. Hasil pengujian model Fixed Effect, keempat variabel independen secara bersama-sama memiliki pengaruh terhadap variabel dependen dengan sebesar 0.734051 atau 73.4\%. Jumlah pengaruh tersebut lebih besar dibandingkan dengan metode Common Effect. Sehingga pada model Fixed Effect tidak terdapat satupun variabel yang memiliki pengaruh signifikan terhadap variabel dependen.

Kemudian, metode Common Effect dan Fixed Effect akan dibandingkan terlebih dahulu sebelum dilanjutkan pada tahap berikutnya untuk mengetahui model mana yang lebih baik antara common effect dengan fixed effect. Maka selanjutnya akan dilakukan pengujian melakukan Redundant Fixed Effect Test (Chow Test). Hasil uji Redundant Fixed Effect didapatkan nilai Cross-section $\mathrm{F}$ adalah 0.0000 atau lebih kecil dari 0,05. Hal ini berarti, hipotesis nol ditolak dan metode estimasi data panel yang digunakan adalah metode fixed effect.Hasil pengujian dengan Redundant Fixed Effect Test dalam memilih model dengan membandingkan common effect modeldengan fixed effect modeladalah fixed effect model dikarenakan hasil R-squared fixed effect lebih besar daripada common effect. Namun, hal ini bukan merupakan hasil akhir dari pemilihan metode pengolahan data. Apabila jumlah data cross section (n) lebih besar dari jumlah data time series (T) maka perlu digunakan metode random effect. Oleh karena itu, penelitian ini akan dilanjutkan dengan membandingkan uji fixed effect dengan random effect.

Setelah melakukan uji Chow, selanjutnya dilakukan pengujian dengan menggunakan uji Hausman. Peneliti dalam melakukan uji Hausman dengan membandingkan fixed effect model dengan random effect model untuk mengetahui uji mana yang paling tepat untuk digunakan dalam penelitian ini.Uji Hausman dapat dilakukan dengan Chi square Statistics. Apabila hasil dari pengujian menunjukkan bahwa Hausman test adalah signifikan, maka metode yang digunakan dalam pengolahan data panel adalah fixed effect model. model random effect, keempat variabel independen secara bersama-sama memiliki pengaruh signifikan terhadap variabel dependennya dengan kontribusi sebesar 0,084783 atau sebesar 8,4\% dimana angka tersebut lebih kecil dibandingkan dengan model fixed asset. Pada model ini terdapat dua variable yang memiliki pengaruh yang signifikan terhadap variabel dependennya yaitu return on equity dan leverage.

Setelah diperoleh hasil dari random effect model, maka selanjutnya akan dilakukan perbandingan antara model fixed effect dengan model random effect dengan menggunakan uji Hausman Specification Test. Uji Hausman merupakan pengujian statistik yang dilakukan untuk mengetahui uji mana yang paling sesuai untuk digunakan dalam penelitian ini.Probability pada cross-section random adalah sebesar 0,0503 atau lebih besar dari 0,05. Sehingga, hasil uji Hausman yang ditampilkan dalam tabel diatas adalah $\mathrm{H0}$ atau Random Effect Model diterima.

Berdasarkan pengujian yang dilakukan diatas dapat disimpulkan bahwa metode yang dipilih dalam penelitian ini adalah Random Effect Model sebagai model yang paling baik digunakan untuk mengestimasi data panel pada penelitian ini. Berdasarkan hasil penelitian yang dilakukan, maka peneliti mencoba memberikan pokok-pokok temuan penelitian secara 
keseluruhan. Hasil Analisis regresi berganda, dapat disimpulkan persamaan model regresi yaitu:

$$
\mathbf{Y}=0.382587+0.001129(\mathrm{SIZE})+0.342465(\mathrm{ROE})-0.114001(\mathrm{LEV})-0.263945(\mathrm{EM})
$$

Dari persamaan diatas, nilai constant sebesar 0.382587. Hal ini menyatakan bahwa variabel SIZE mengalami kenaikan sebanyak 1 satuan dan variabel ROE, LEV, EM dianggap konstan, maka Dividend PayoutRatio akan naik sebesar 0.001129 satuan, ROE mengalami kenaikan sebanyak 1 satuan dan variabel SIZE, LEV, EM dianggap konstan, maka Dividend PayoutRatio akan naik sebesar 0.342465 satuan, LEV mengalami kenaikan sebanyak 1 satuan dan variable SIZE, ROE, EM dianggap konstan, maka Dividend PayoutRatio akan turun sebesar 0.114001 satuan dan EM mengalami kenaikan sebanyak 1 satuan dan variable SIZE, ROE, LEV dianggap konstan, maka Dividend PayoutRatio akan turun sebesar 0.263945 satuan.

Uji t (parsial) adalah uji yang digunakan untuk menguji keterkaitan secara individu antara variabel bebas dengan variabel terikat. Untuk menguji hipotesis nol ditolak atau diterima, titik tolaknya adalah bila nilai $p$-value $t$-test $<$ atau $>0,05$, artinya jika nilai signifikansi dari variabel independen di bawah 0,05 , maka $\mathrm{H}_{0}$ ditolak dan $\mathrm{H}_{\mathrm{a}}$ diterima dan sebaliknya. Hasil uji ini dapat dilihat pada tabel dibawa ini.

Tabel 1. Hasil Uji secara Parsial (Uji-t)

\begin{tabular}{|c|c|c|c|c|}
\hline \multicolumn{5}{|c|}{$\begin{array}{l}\text { Dependent Variable: DP? } \\
\text { Method: Pooled EGLS (Cross-section random effects) } \\
\text { Date: } 1 / 06 / 17 \text { Time: } 14: 36 \\
\text { Sample: } 20142016 \\
\text { Included observations: } 3 \\
\text { Cross-sections included: } 39 \\
\text { Total pool (balanced) observations: } 117 \\
\text { Swamy and Arora estimatorof component variances }\end{array}$} \\
\hline Variable & Coefficient & Std. Error & t-Statistic & Prob. \\
\hline O & 0.382587 & 0.854208 & 0.447885 & 0.6551 \\
\hline SIZE? & 0.001129 & 0.029036 & 0.038876 & 0.9691 \\
\hline ROE? & 0.342465 & 0.155370 & 2.204187 & 0.0296 \\
\hline LEV? & -0.114001 & 0.043982 & -2.592008 & 0.0108 \\
\hline EM? & -0.263945 & 0.290533 & -0.908486 & 0.3656 \\
\hline
\end{tabular}

Untuk mengetahui korelasi variabel-variabel independen terhadap variabel dependen, maka dilakukan uji korelasi (R). Dalam penelitian ini menunjukkan nilai $R$ sebesar 0.191057 . Hal ini menunjukkan bahwa hubungan independen variabel dengan dependen variabel dan Uji Koefisien Determinasi (Adj. R-Square )yang digunakan untuk mengetahui persentase sumbangan variabel bebas secara serentak terhadap variabel terikat menunjukkan angka 19.12\%. Jadi, dapat disimpulkan bahwa $19.12 \%$ varabel independen terhadap variabel dependen yang digunakan dalam model ini.

Diskusi. Hasil dari penelitian ini menunjukkan bahwa earnings management dan firm size berpengaruh tidak signifikan terhadap dividend payoutratio, sedangkanreturn on equity dan leverage berpengaruh signifikan terhadap dividend payoutratio.

\section{PENUTUP}

Berdasarkan hasil pengujian data dalam penelitian ini, struktur modal perusahaan manufaktur di Indoenesia yang terdaftar di Bursa Efek Indonesia periode 2014-2016 
menunjukkan bahwa variabel Earnings Management (EM) memiliki pengaruh negatif tidak signifikan terhadap dividend payout ratio pada perusahaan manufaktur yang terdaftar terdaftar di Bursa Efek Indonesia tahun 2014-2016. Pengaruh earnings management yang tidak signifikan menunjukkan bahwa kenaikan maupun penurunan earnings management tidak akan membawa perubahan besar terhadap dividend payout, variabel Firm size (SIZE) yang di proxy kan dengan Natural Log Total Asset memiliki pengaruh positif tidak signifikan terhadap dividend payout ratio pada perusahaan manufaktur yang terdaftar terdaftar di Bursa Efek Indonesia tahun 2014-2016. Pengaruh Firm size yang tidak signifikan terhadap dividend payout ratio menunjukkan bahwa kenaikan maupun penurunan firm size tidak akan membawa perubahan yang besar terhadap dividend payout ratio, variabel Return On Equity (ROE) yang di proxy kan dengan membandingkan antara laba bersih sesudah pajak dengan total ekuitas perusahaan memiliki pengaruh positif signifikan terhadap dividend payout ratio pada perusahaan manufaktur yang terdaftar terdaftar di Bursa Efek Indonesia tahun 2014-2016. Pengaruh Return On Equity yang signifikan menunjukkan bahwa kenaikan ataupun penurunan Return On Equity akan membawa perubahan besar terhadap dividend payout ratio, variabel Leverage (LEV) yang di proxy kan dengan membandingkan antara total kewajiban dengan total ekuitas perusahaan memiliki pengaruh negatif signifikan terhadap dividend payout ratio pada perusahaan manufaktur yang terdaftar terdaftar di Bursa Efek Indonesia tahun 2014-2016. Pengaruh leverage yang signifikan terhadap dividend payout ratio menunjukkan bahwa ketika nilai leverage mengalami kenaikan ataupun penurunan, hal ini akan membawa perubahan besar terhadap dividend payout ratio.

Keterbatasan. Keterbatasan dari penelitian ini dikarenakan: (1) Periode pengamatan sampel dalam penelitian ini terbatas hanya tiga tahun, yaitu tahun 2014-2016, (2) Populasi perusahaan yang dapat dijadikan sampel dalam penelitian ini hanya perusahaan yang bergerak dalam industri manufaktur dengan jumlah sampel perusahaan yang terbatas, yaitu 39 perusahaan, sehingga penelitian mengenai dividend payout ratio terbatas pada perusahaan yang bergerak pada industri manufaktur saja, (3) Penelitian ini hanya menggunakan empat variabel independen dalam meneliti faktor-faktor yang mempengaruhi dividend payout ratio yaitu earnings management, firm size, return on equity, leverage, dan firm size.

Saran. Berdasarkan hasil dan keterbatasan di atas, maka saran yang dapat diberikan untuk melakukan penelitian selanjutnya yaitumemperpanjang periode penelitian agar dapat melihat tren kenaikan maupun penurunan dari satu periode ke periode lain sehingga dapat memperoleh hasil yang lebih akurat pada dividend payout ratio, memperluas populasi penelitian dengan memperbesar cakupan sektor seluruh perusahaan yang terdaftar di Bursa Efek Indonesia serta menambah variabel independen yang berbeda seperti return on asset, debt to equity, dan assetsgrowth yang berpengaruh pada dividedn payout ratio.

\section{DAFTAR RUIJUKAN}

Abdul Halim. (2009). Analisis Investasi. Jakarta: Salemba Empat.

Agus Widarjono. (2009). Ekonometrika Pengantar dan Aplikasinya. Edisi Ketiga.Yogyakarta: Ekonisia. 
Ahmed, Ibrahim Elsiddig. (2015). "Liquidity, Profitability and the Dividends Payout Policy". World Review of Business Research, 5(2), 73 - 85.

Ahmed Arif, Afsheen Abrar, Mehwish Aziz Khan, Ferheen Kayani and Syed Zulfiqar Ali Shah, (2011). "Dividend Policy and Earnings Management: An Empirical Study of Pakistani Listed Companies", published in Information Management and Business Review, 3(2),68-77.

Brigham dan Houston.(2010). Dasar-dasar Manajemen Keuangan Buku 1. Edisi Sebelas. Jakarta: Salemba Empat.

Dedi Rosadi. (2012). Ekonometrika dan Analisis Runtun Waktu Terapan dengan Eviews. Yogyakarta: Andi Offset

Dennis, D., \& Osobov, I. (2007). Why Do Firms Pay Dividends? International Evidence on the Determinants of Dividend Policy.

Dewi, Ayu Sri Mahatma dan Ary Wirajaya. (2013). Pengaruh Struktur Modal, Profitabilitas dan Ukuran Perusahaan terhadap Nilai Perusahaan. E-Journal Akuntansi Universitas Yudayana, 358-372.

Drs. Jumingan. (2017). Analisis Laporan Keuangan. Jakarta : Bumi Aksara

Ghozali, Imam. (2012). Aplikasi Analisis Multivariate dengan Program IBM SPSS. Yogyakarta: Universitas Diponegoro

Gordon,Myron J. dan Lintner, John. (1963). Optimal Investment and Financing Policy. Journal of Finance. 18: 264-272.

Harahap, Sofyan Syafri, (2015), Analisis Kritis Atas Laporan Keuangan, Cetakan Kedua Belas, Jakarta: Raja Grafindo Persada.

Hery. (2016). Analisis Laporan Keuangan. Jakarta: Grasindo.

Fahmi, Irham (2015). Analisis Laporan Keuangan Cetakan Kelima. Bandung: C.V Alfabeta.

Kajola, O. Sunday, Ajibola A. Desu, Tobechi F. Agbanike. (2015). "Factors Influencing Dividend Payout Policy Decisions of Nigerian Listed Firms". International Journal of Economics, Commerce, and Management. III (6), 539-57.

Kasmir. (2017). Analisis Laporan Keuangan. Jakarta: Raja Grafindo.

Khanna, Manisha dan Khanna, Monika. (2015). "Impact of Earnings Management on Dividend Policy of Indian Companies". International Journal of Multidisciplinary Research and Development. 2(1), 352-356.

Kristiani, Kadek Emi, et al. (2014). "Pengaruh Mekanisme Corporate Governance dan Ukuran Perusahaan Terhadap Manajemen Laba pada Perusahaan Manufaktur yang Terdaftar di BEI". e- Jurnal S1 Ak Universitas Pendidikan Ganesha. 2(1).

Kurniasih, Tommy dan Maria M. Ratna Sari. (2013). "Pengaruh Return On Asset (ROA), Leverage, Corporate Governance, Ukuran Perusahaan dan Kompensasi Rugi Fiskal pada Tax Avoidance". Buletin Studi Ekonomi, 18(1), 58-66.

Ludijanto, Shella Ekawati, S R Handayani,R R Hidayat. (2014). "Pengaruh Analisis Leverage Terhadap Kinerja Keuangan Perusahaan (Studi Pada Perusahaan Property Dan Real Estate Yang Listing Di BEI Tahun 2010- 2012)". Jurnal Administrasi Bisnis (JAB). 8(1).

Nuhu Eliasu, Abubakar Musah, Damankah Basil Senyo. (2014). "Determinants of Dividend Payout of Financial Firms and Non-Financial Firms in Ghana". International Journal of Academic Research in Accounting, Finance and Management Sciences. 4(3).

Nurhayati, M. (2013). Profitabilitas, Likuiditas, dan Ukuran Perusahaan Pengaruhnya Terhadap Kebijakan Dividen dan Nilai Perusahaan Sektor Non Jasa. Jurnal Keuangan dan Bisnis. 5(2). 
Ranti, Uwuigbe Olubukunola. (2013). "Determinants of Dividend Policy: A study of selected listed Firms in Nigeria". Journal Department of Accounting School of Business College of Development Studies Covenant University Ogun Sta Scott, William R, (2009). Financial Accounting Theory. Fifth Edition. Canada Prentice Hall. Shehu Musa, Hasnah Kamardin, Haruna Shehu. (2015). "The relationship between dividen payout ratio and outside directors among Malaysian public lited companies". European Journal of Accounting, Auditing and Finance Research. 3(10).

Wahyudi Agus. (2016). "Analisis Faktor-Faktor yang Mempengaruhi Kebijakan Dividen Pada Perusahaan go public di BEI”. Skripsi. Kediri: Universitas Nusantara PGRI Kediri.

$\underline{\text { www.idx.co.id }}$

www.sahamok.com 
Hastuti: Pengaruh EM, ROE dan LEV Terhadap DPR pada Perusahaan Perusahaan... 
Hastuti: Pengaruh EM, ROE dan LEV Terhadap DPR pada Perusahaan Perusahaan...

e

